\title{
Effects of local treatment with and without sensorimotor and balance exercise in individuals with neck pain: protocol for a randomized controlled trial
}

\author{
Munlika Sremakaew ${ }^{1}$, Gwendolen Jull ${ }^{2}$, Julia Treleaven ${ }^{2}$, Marco Barbero ${ }^{3}$, Deborah Falla ${ }^{4}$
} and Sureeporn Uthaikhup ${ }^{1 *}$

\begin{abstract}
Background: Impaired cervical joint position sense and balance are associated with neck pain. Specific therapeutic exercise and manual therapy are effective for improving neck pain and functional ability but their effects on joint position sense and balance impairments remain uncertain. Changes in the joint position sense and balance may need to be addressed specifically. The primary objective is to investigate the most effective interventions to improve impaired cervical joint position sense and balance in individuals with neck pain. The secondary objective is to assess the effectiveness of the interventions on pain intensity and disability, pain location, dizziness symptoms, cervical range of motion, gait speed, functional ability, treatment satisfaction and quality of life.
\end{abstract}

Methods: A $2 \times 2$ factorial, single blind RCT with immediate, short- and long-term follow-ups. One hundred and sixty eight participants with neck pain with impaired joint position sense and balance will be recruited into the trial. Participants will be randomly allocated to one of four intervention groups: i) local neck treatment, ii) local treatment plus tailored sensorimotor exercises, iii) local treatment plus balance exercises, and iv) local treatment plus sensorimotor and balance exercises. Participants receive two treatments for 6 weeks. Primary outcomes are postural sway and cervical joint position error. Secondary outcomes include gait speed, dizziness intensity, neck pain intensity, neck disability, pain extent and location, cervical range of motion, functional ability, perceived benefit, and quality of life. Assessment will be measured at baseline, immediately after treatment and at 3, 6, 12 month-follow ups.

Discussion: Neck pain is one of the major causes of disability. Effective treatment must address not only the symptoms but the dysfunctions associated with neck pain. This trial will evaluate the effectiveness of interventions for individuals with neck pain with impaired cervical joint position sense and balance. This trial will impact on clinical practice by providing evidence towards optimal and efficient management.

Trial registration: ClinicalTrials.gov (NCT03149302). May 10, 2017.

Keywords: Balance, Exercises, Manual therapy, Neck pain, Sensorimotor control

\footnotetext{
* Correspondence: sureeporn.uthaikhup@cmu.ac.th

${ }^{1}$ Department of Physical Therapy, Faculty of Associated Medical Sciences,

Chiang Mai University, Chiang Mai, Thailand

Full list of author information is available at the end of the article
} 


\section{Background}

Neck pain is a common musculoskeletal disorder and a costly public health issue $[1,2]$. The pain is often persistent or recurrent in nature $[3,4]$. The underlying mechanisms for recurrence or persistence remain unclear but could be associated with altered proprioception from the neck muscles, which have a vital and unique role in providing input for cervical joint position sense, head and eye movement control and postural stability [5-7]. Patients with neck pain not uncommonly experience symptoms of dizziness/light headedness and unsteadiness [8, 9]. Such patients usually have impaired proprioception (cervical joint position sense) and postural instability which account for these symptoms [10-13]. These impairments can lead to decreased physical performance and increased concerns of falling, particularly the elderly $[14,15]$. Further, dizziness and unsteadiness have been shown to be predictors of both poorer recovery [16] and poorer response to musculoskeletal treatment [17-19]. Thus it is important to address such symptoms and disturbances in patients with neck pain not only to gain symptomatic relief but also to reverse the impairments to improve physical performance and function.

Evidence suggests that conventional treatment of manual therapy and specific therapeutic exercise directed towards neuromuscular impairments are effective interventions for relieving neck pain $[20,21]$ and dizziness symptoms $[22,23]$ and they improve cervical joint mobility and neck muscle performance [24-26]. However, these interventions are not specifically directed towards impaired cervical proprioception and balance. The effects of exercise and manual therapy on proprioception (joint reposition sense) and balance remain uncertain $[23,24,27]$.

It is recommended that changes in cervical joint position sense and balance are addressed to optimize outcomes [23, 28]. There is preliminary evidence to suggest that sensorimotor training can improve impaired cervical joint position sense [29-32], but it is unknown if sensorimotor training can improve balance or indeed if balance training can resolve impairments in cervical joint position sense. Is one, both or neither training required in addition to conventional treatment to treat patients with neck pain and proprioceptive and balance disturbances? This is an important question as it is necessary to not only understand treatment effects but also to develop the most efficient treatment strategies.

This is a mechanistic randomized clinical trial in which the effects of treatment on measures of balance and cervical proprioception will be examined. This trial will evaluate the short- and long-term benefits of conventional local treatment to the neck with and without additional sensorimotor control and balance exercise approaches for people with chronic neck pain. The primary objective is to investigate the most effective and efficient interventions to improve disturbances in cervical joint position sense and balance. More specifically, we will test if local treatment to the neck (manual therapy and therapeutic exercise) is sufficient, or whether the addition of sensorimotor control and balance exercise has a superior effect. As it is unclear whether sensorimotor control exercises will automatically improve balance and vice versa, we will also test their effects separately as well as collectively. To achieve our objective, we will test four treatment groups: (i) local neck treatment alone, (ii) local treatment plus tailored sensorimotor control exercises (joint position sense and oculomotor control), (iii) local treatment plus balance exercises and (iv) local treatment plus both sensorimotor control and balance exercises. The secondary objective is to assess the effectiveness of the interventions on neck pain intensity, neck disability, pain extent and location, any dizziness symptoms, cervical range of motion, gait speed, functional ability, treatment satisfaction and quality of life.

\section{Study hypotheses}

Primary hypothesis: Specific training of impairments in sensorimotor control and balance will be superior for improving impairments in neck proprioception and balance.

Secondary hypothesis: Specific training of impairments in sensorimotor control and balance will be superior for reducing dizziness intensity and increasing gait speed. There will be no differences between intervention groups in outcomes of neck pain intensity, neck disability, pain extent and location, cervical range of motion, functional ability, treatment satisfaction and quality of life.

\section{Methods/design}

\section{Trial design}

The trial utilizes a single blind $2 \times 2$ factorial design, and conforms to the CONSORT recommendations [33].

\section{Participants}

A sample of 168 women and men aged 18 years and older with neck pain and JPS and balance impairments will be recruited from the communities in Chiang Mai province, Thailand by advertising through community centers, radio, and Facebook, placing posters in hospitals, physiotherapy clinics and universities, and using our database of participants with neck pain who participated in previous studies and have given consent for future contact. Participants who respond to the advertisements will be screened by a research assistant via telephone interview. They will be potentially eligible for the trial if they meet the eligibility criteria (Table 1).

For those provisionally eligible for the trial, appointments will be made with an experienced physiotherapist who will be blinded to participant group allocation if accepted for the trial. The experienced physiotherapist will perform a 
Table 1 Inclusion and exclusion criteria

Inclusion criteria
- Aged $\geq 18$ years
- Insidious neck pain for at least 3 months
- Average neck pain intensity over the past week $\geq 30 \mathrm{~mm}$ (100 mm
visual analogue scale)
- Score $\geq 10 / 100$ on the Neck Disability Index-Thai version (NDI-TH)
[47]
Exclusion criteria
- Previous history of neck and head trauma or surgery
- Known or suspected vestibular pathology, vertigo or dizziness from
ear or brain disorders, sensory nerve pathways (e.g. BPPV), or vascular
disorders (e.g. migraine, hypertension)
- Any musculoskeletal or neurological conditions that could affect
balance
- Inflammatory joint disease
- Systemic conditions
- Cognitive impairment
- Taking four or more medications
- Received physiotherapy treatment for their neck disorder in the past
12 months

physical examination of the neck and test sensorimotor function and balance. The physical examination includes:

1) Tests of cervical joint position error (JPE) [9, 13]. The task is to return to the starting position as accurately as possible with the blindfold. Three trials will be performed of right and left rotation and extension. An average absolute error of $>4.5^{\circ}$ in any direction is indicative of a deficit in cervical joint position sense [34].

2) Tandem stand test [35]. The participants stand heel to toe with the dominant foot behind the nondominant foot on a firm surface with eyes closed (age $\leq 45$ years) or with eyes open (age $>45$ years) [36]. An inability to maintain the standing position without taking a step for $30 \mathrm{~s}$ indicates balance impairment [36].

3) Manual examination of the cervical spine. The physiotherapist will palpate the cervical facet joints from C0-1 to C7-T1 bilaterally. A joint will be classified as symptomatic by a combination of pain provoked $>2 / 10$ and the physiotherapist's rating of at least moderately abnormal tissue resistance [37].

All participants will be provided information about the study and enrolled into the trial if they meet all eligibility criteria and voluntarily sign an informed consent statement.

\section{Procedure}

Eligible participants who have agreed to participate in the study will be randomly allocated to one of four treatment groups; local neck treatment (cervical mobilization and therapeutic exercise), local neck treatment combined with sensorimotor control exercises, local neck treatment combined with balance exercises, or local neck treatment combined with sensorimotor control and balance exercises. Interventions will be provided in 12 physiotherapy sessions over a 6-week intervention period ( 2 visits per week) [26]. Baseline and follow-up assessments (post-treatment and 3, 6 and 12 months) will be conducted at the Department of Physical Therapy, Chiang Mai University by an assessor who is blinded to treatment allocation. The participants will be requested to refrain from seeking other forms of treatment during the trial. Medication for pain may be taken, if necessary, but the participants will be asked to record the type and dose of medication in a medication diary. The flow chart of the trial is presented in Fig. 1.

\section{Physiotherapist training and treatment fidelity}

The interventions will be provided by five physiotherapists who are experienced in the trial interventions and who have at least 5 years clinical experience in musculoskeletal physiotherapy. Each physiotherapist will deliver all intervention arms. The physiotherapists will attend a $3 \mathrm{~h}$ training session to enhance standardization of the interventions. The physiotherapists will be randomly assigned to each participant using computerized random numbers. Training will be provided by an experienced musculoskeletal physiotherapist and trial physiotherapists will receive a detailed procedural and treatment manual. Participant case notes will be monitored as will be selected. Treatment sessions will be audited to ensure that the physiotherapists are managing patients as per the trial treatment protocols.

\section{Intervention programs}

Treatment will commence within one week of the baseline assessment. Each session in the intervention programs will last approximately 30-60 min depending on group allocation. The participants in each treatment group will be asked to practice their prescribed exercises once daily for 6 weeks and complete an exercise diary to monitor compliance and record adverse events. The physiotherapist will provide the elements of treatment and a home exercise program based on the initial and progressive assessment of participant's cervical joint, muscular, and sensorimotor and balance dysfunctions (as relevant to group allocation). Description of the intervention programs are summarized in Tables 2 and 3 . Exercise prescription and progression are presented in Table 4. The physiotherapist will progress the participants exercise programs to the next level once they have achieved the target of the current level. 


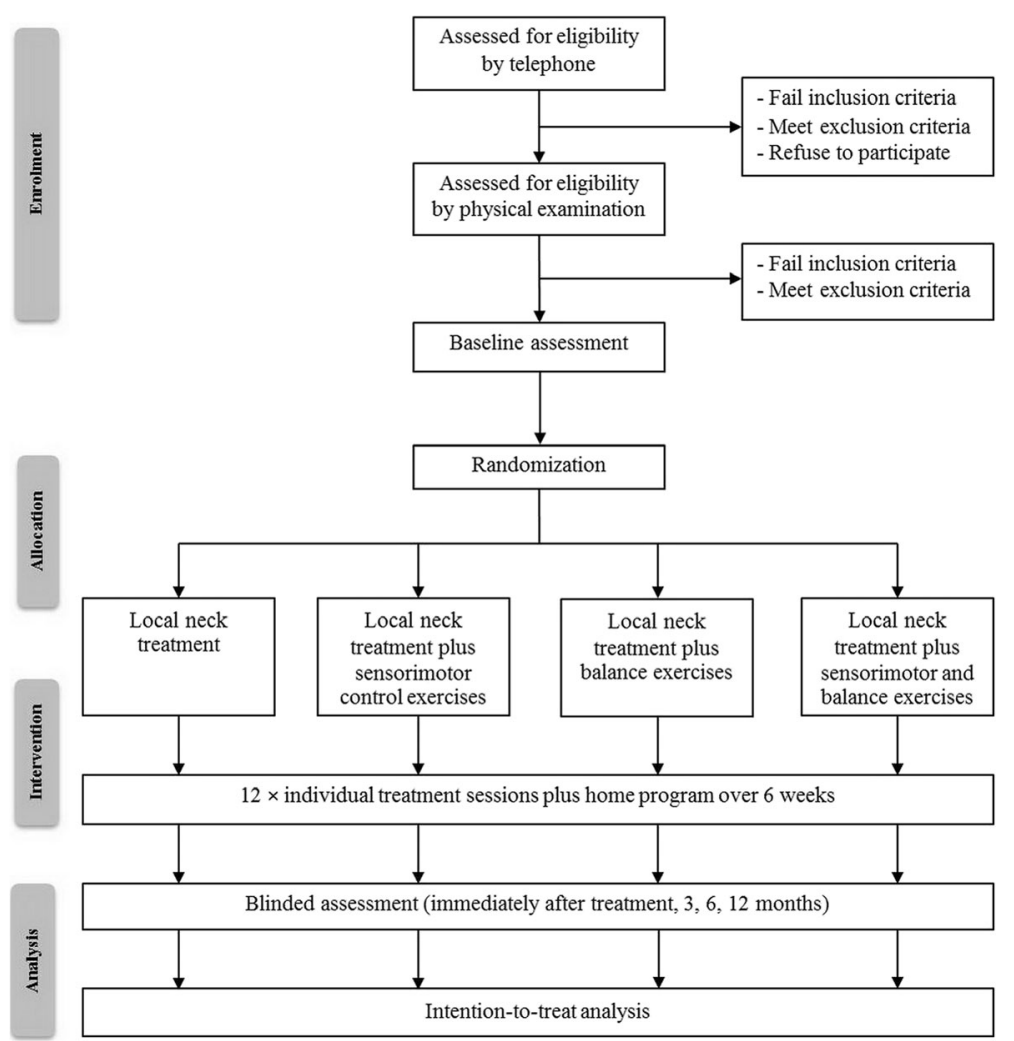

Fig. 1 Flow diagram of the trial protocol

\section{Outcome measures (Table 5) Primary outcomes}

Postural stability A sway meter will be used to measure the extent of postural sway and displacement. The sway meter is a simple tool for assessing postural sway in

Table 2 Description of the intervention programs

\begin{tabular}{|c|c|c|}
\hline Intervention & Description & Time (minutes) \\
\hline \multirow[t]{2}{*}{ Local neck treatment } & Cervical mobilization & 10 \\
\hline & $\begin{array}{l}\text { Specific therapeutic } \\
\text { exercises }\end{array}$ & 20 \\
\hline \multirow{3}{*}{$\begin{array}{l}\text { Local treatment } \\
\text { plus sensorimotor } \\
\text { control exercises }\end{array}$} & Cervical mobilization & 10 \\
\hline & $\begin{array}{l}\text { Specific therapeutic } \\
\text { exercises }\end{array}$ & 20 \\
\hline & Sensorimotor exercises & 15 \\
\hline \multirow{3}{*}{$\begin{array}{l}\text { Local treatment plus } \\
\text { balance exercises }\end{array}$} & Cervical mobilization & 10 \\
\hline & $\begin{array}{l}\text { Specific therapeutic } \\
\text { exercises }\end{array}$ & 20 \\
\hline & Balance exercises & 15 \\
\hline \multirow{4}{*}{$\begin{array}{l}\text { Local neck treatment } \\
\text { plus sensorimotor control } \\
\text { and balance exercises }\end{array}$} & Cervical mobilization & 10 \\
\hline & $\begin{array}{l}\text { Specific therapeutic } \\
\text { exercises }\end{array}$ & 20 \\
\hline & Sensorimotor exercises & 15 \\
\hline & Balance exercises & 15 \\
\hline
\end{tabular}

individuals with impaired balance [38]. It has been shown to have good test-retest reliability (ICCs $=0.65$ 0.94) and good validity ( $\mathrm{r}$ with forceplate $=0.56-0.87$ ) [38]. The sway meter consists of a $40 \mathrm{~cm}$ long rod with a vertically mounted pen at its end. It will be firmly attached to the participant's waist using a webbing strap. During the test, the pen will record participant's sway on a millimeter graph paper fastened to the top of an adjustable-height table. Maximum displacement in anterior-posterior (APmax) and medial-lateral (MLmax) directions and total sway (number of square millimeter squares traversed by the pen) will be recorded. The postural sway will be measured in 8 conditions as follows: narrow stance (feet close together) on firm and soft surfaces with eyes open and eyes closed [39] and during a neck torsion maneuver (head turned $45^{\circ}$ to the left and right) on firm and soft surfaces [40]. Participants will be tested barefoot and asked to stand still without talking for 30s for each condition. Participants are allowed a maximum of two additional attempts if they are unable to maintain the position for $30 \mathrm{~s}$. A rest period of $60 \mathrm{~s}$ will be given between each condition.

Cervical JPE Cervical JPE will be measured using a laser-pointer attached to a lightweight headband as described by Revel et al. [13]. Participants will be seated 
Table 3 Description of modalities used in the intervention programs

\begin{tabular}{ll}
\hline Modality & Description \\
\hline Cervical mobilization [57] & Low-velocity passive mobilization techniques to the symptomatic cervical segments as determined by the \\
physiotherapist's clinical examination. Physiotherapists are free to select from what are termed passive \\
accessory and physiological movement techniques as deemed relevant to the individual participant based \\
on the initial and progressive reassessments.
\end{tabular}

Specific therapeutic exercises $[26,58,59]$ Cervical flexors

(i) Train craniocervical flexor (CCF) activation and holding capacity. Participants learn the correct movement and train to hold the contraction with and without feedback in progressively more difficult inner range positions.

(ii) Train the interaction of deep and superficial cervical flexors in movement patterning and functional tasks.

(iii) Train co-contraction of the deep cervical flexors and extensors.

(iv) Train strength and endurance of the cervical flexors.

Cervical extensors

(i) Train craniocervical extensors and rotators (head extension, head rotation $<40^{\circ}$ ) with the cervical spine in a neutral position.

(ii) Train cervical extension to bias the cervical extensors (extend cervical spine keeping the craniocervical region in a neutral position)

(iii) Train strength and endurance.

Axioscapular muscles

(i) Train scapular muscles in particular the upper/ middle/ lower trapezius and serratus anterior in both open and closed chain positions, with and without load and movement of the upper limb.

(ii) Train correct scapular posture.

Postural correction exercise

(i) Train a neutral spinal posture from first treatment.

(ii) Train scapulothoracic and cervical postures. Participants train to actively correct their posture and maintain for 10s. Practice is in sitting, standing (2-3 times an hour).

Sensorimotor exercises $[7,59]$

Cervical JPS. The participants practice moving their head to points in different directions initially with eyes open, using a laser pointer mounted onto a lightweight headband. This practice will involve relocating the head back to a neutral posture or to predetermined points in range. The exercise is progressed by closing the eyes and by changing directions and ranges of movement.

Cervical movement sense. The participants practice tracing horizontal and vertical lines on a chart on the wall focusing on accuracy and secondarily speed using a laser pointer mounted onto a lightweight headband for feedback on performance. Exercises are progressed by increasing speed and tracing more intricate patterns such as a figure of eight, zig-zag or an alphabet pattern.

Oculomotor control exercises

(i) Train eye follow. The participants follow a target moving from side to side and up and down while keeping their head still.

(ii) Train gaze stability exercises. The participants perform active movements, while fixing their gaze on the target. Progressions include increasing the target's speed, changing the participant's position and changing visual background and focus point.

(iii) Train eye head co-ordination exercises. The participants move their eyes and head in the same direction to focus on a target. Progressions include moving the eyes first then the head and moving eyes and head in opposite directions.

Balance exercises $[7,59]$

The training starts with static balance and progresses to dynamic balance and challenging gait. The exercises will be progressed by closing the eyes, altering the support surface (i.e. a soft surface), concurrent voluntary movements, or increasing speed.

$90 \mathrm{~cm}$ away from the target. They will be blindfolded and asked to perform an active movement (extension and rotation to the left and right) and return to the starting head position as accurately as possible. An absolute error between the starting and end points will be calculated in millimeters and then converted to degrees. Three repetitions of each movement direction will be undertaken and the mean value of the error will be used for analysis. This method has been shown to have good test-retest reliability $(\mathrm{ICCs}=0.73-0.84)$ and high validity ( $\mathrm{r}$ with three-dimensional ultrasound based technique $=0.95)$ [41].

\section{Secondary outcomes}

Gait speed: Participants will be instructed to walk barefoot over $10 \mathrm{~m}$ at a comfortable speed and then with 
Table 4 Details of the exercise progression

\begin{tabular}{|c|c|c|c|}
\hline Exercise & Level & Details & Targeted repetitions \\
\hline \multirow[t]{18}{*}{ Cervical flexors } & 1 & Re-education of CCF movement pattern & \\
\hline & & Supine, knees bent & \\
\hline & & - Gentle and controlled nodding action facilitated with eye movement & 10 reps \\
\hline & & Holding capacity & \\
\hline & & Supine, knees bent & \\
\hline & & - Repeated and sustained CCF progressing from 22 to $30 \mathrm{mmHg}$ & $10 \mathrm{~s}$ holds $\times 10$ reps \\
\hline & 2 & Interaction between the deep/superficial cervical flexors & \\
\hline & & Sitting & \\
\hline & & - Controlled head movement through range of extension and return to neutral & 10 reps \\
\hline & & Co-contraction of the deep cervical flexors/extensors & \\
\hline & & Sitting & \\
\hline & & - Isometric cervical rotation facilitated with eye movement (left/right sides) & $5 \mathrm{~s}$ holds $\times 5$ reps \\
\hline & 3 & Strength/endurance of the cervical flexors & \\
\hline & & Sitting & \\
\hline & & - Isometric CCF in a range of cervical extension & $10 \mathrm{~s}$ holds $\times 10$ reps \\
\hline & & - Lifting the head off the wall (with the chair up to $30 \mathrm{~cm}$ away from the wall) & $10 \mathrm{~s}$ holds $\times 10$ reps \\
\hline & & Supine & \\
\hline & & - Lifting the head off a pillow (2, 1 then 0 pillows as per participant's capacity) & 10 s holds $\times 10$ reps \\
\hline \multirow[t]{12}{*}{ Cervical extensors } & 1 & Re-education of extension movement pattern & \\
\hline & & Prone on elbows/four-point kneeling positions & \\
\hline & & - Craniocervical extension & 3 sets of 5 reps \\
\hline & & - Craniocervical rotation $\left(<40^{\circ}\right)$ & 3 sets of 5 reps \\
\hline & & - Cervical extension while keeping the craniocervical region in a neutral position & 3 sets of 5 reps \\
\hline & 2 & Co-contraction of the deep cervical flexors/extensors & \\
\hline & & Sitting & \\
\hline & & - Isometric cervical rotation facilitated with eye movement (left/right sides) & $5 \mathrm{~s}$ holds $\times 5$ reps \\
\hline & 3 & Strength/endurance of the cervical extensors & \\
\hline & & Prone on elbows/four-point kneeling positions & \\
\hline & & - Isometric hold in range of cervical extension & 10 s holds $\times 10$ reps \\
\hline & & - Addition of progressive load (light weights attached to head) as per patient's capacity & \\
\hline \multirow[t]{14}{*}{ Axioacapular control } & 1 & Re-education of scapular movement control & \\
\hline & & Side lying with arm elevated $140^{\circ} /$ sitting & \\
\hline & & - Passive repositioning of the scapular & 10 reps \\
\hline & & - Active repositioning of the scapular & 10 reps \\
\hline & & Holding capacity & \\
\hline & & Side lying with arm elevated $140^{\circ} /$ sitting & \\
\hline & & - Active repositioning the scapular posture and isometric hold & $10 \mathrm{~s}$ holds $\times 10$ reps \\
\hline & 2 & Axioscapular muscle control & \\
\hline & & Sitting & \\
\hline & & - Arm movement without load (external rotation/abduction/flexion $<30^{\circ}$ ) & 10 reps \\
\hline & & - Arm movement without load throughout range & 10 reps \\
\hline & & Prone on elbows/four-point kneeling position & \\
\hline & & - Thoracic lift (serratus anterior) and isometric hold & 5 s holds $\times 5$ reps \\
\hline & 3 & Strength/endurance of axioscapular muscles & \\
\hline
\end{tabular}


Table 4 Details of the exercise progression (Continued)

\begin{tabular}{|c|c|c|c|}
\hline Exercise & Level & Details & Targeted repetitions \\
\hline & & Sitting & \\
\hline & & - Arm movement with load (external rotation/abduction/flexion $<30^{\circ}$ ) & 10 reps \\
\hline & & - Arm movement with load throughout the range & 10 reps \\
\hline & & Prone & \\
\hline & & - Lift the shoulder off the bed and hold without arm load & 10 s holds $\times 10$ reps \\
\hline & & - Lift the shoulder off the bed and hold with arm load & 10 s holds $\times 10$ reps \\
\hline \multirow[t]{9}{*}{ Postural correction } & 1 & Correction of spinal posture & \\
\hline & & Sitting & \\
\hline & & - Active upright sitting initiated with lumbo-pelvic movement & 10 s holds $\times 10$ reps \\
\hline & 2 & Correction of spinal posture and scapular orientation & \\
\hline & & Sitting & \\
\hline & & - Actively positioning the scapular in a neutral posture while maintaining spinal posture & 10 s holds $\times 10$ reps \\
\hline & 3 & Spinal and scapular correction plus occipital lift & \\
\hline & & Sitting & \\
\hline & & - Actively lengthen the back of the neck while maintaining spinal and scapular posture & 10 s holds $\times 10$ reps \\
\hline \multirow[t]{13}{*}{ Cervical joint position sense } & 1 & Relocation with laser feedback & \\
\hline & & Sitting & \\
\hline & & - Head relocating to neutral position with eyes opened (vertical/horizontal) & 5 reps $\times 3$ sets \\
\hline & & - Head relocating to predetermined position in range with eyes opened (vertical/horizontal) & 5 reps $\times 3$ sets \\
\hline & 2 & Relocation with laser feedback & \\
\hline & & Sitting & \\
\hline & & - Head relocating to neutral position with eyes opened (diagonal) & 5 reps $\times 3$ sets \\
\hline & & - Head relocating to predetermined position in range with eyes opened (diagonal) & 5 reps $\times 3$ sets \\
\hline & & - Head relocating to specific targets with eyes opened (all directions) & 5 reps $\times 3$ sets \\
\hline & 3 & Relocation with laser feedback & \\
\hline & & Sitting & \\
\hline & & - Head relocating to neutral position with eyes closed (all directions) & 5 reps $\times 3$ sets \\
\hline & & - Head relocating to predetermined position in range with eyes closed (all directions) & 5 reps $\times 3$ sets \\
\hline \multirow[t]{9}{*}{ Cervical movement sense } & 1 & Movement sense training with laser feedback & \\
\hline & & Sitting & \\
\hline & & - Tracing a line (vertical/horizontal) & 5 reps $\times 3$ sets \\
\hline & 2 & Movement sense training with laser feedback & \\
\hline & & Sitting position & \\
\hline & & - Tracing an intricate pattern at a slow speed (a figure of eight/zig-zag/alphabet) & 5 reps $\times 3$ sets \\
\hline & 3 & Movement sense training with laser feedback & \\
\hline & & Sitting position & \\
\hline & & - Tracing an intricate pattern at a fast speed (a figure of eight/zig-zag/alphabet) & 5 reps $\times 3$ sets \\
\hline \multirow[t]{7}{*}{ Oculomotor control } & 1 & Eye follow, gaze stability and eye-head coordination & \\
\hline & & Sitting & \\
\hline & & - Eyes following a target with slow speed while keeping the head still (vertical/horizontal) & 5 reps $\times 3$ sets \\
\hline & & - Head moving while fixing eyes on a single spot (vertical/horizontal) & 5 reps $\times 3$ sets \\
\hline & & - Eyes and head moving together to the same direction (vertical/horizontal) & 5 reps $\times 3$ sets \\
\hline & 2 & Eye follow, gaze stability and eye-head coordination & \\
\hline & & Sitting & \\
\hline
\end{tabular}


Table 4 Details of the exercise progression (Continued)

\begin{tabular}{|c|c|c|c|}
\hline Exercise & Level & Details & Targeted repetitions \\
\hline & & - Eyes following a target with fast speed while keeping the head still (vertical/horizontal) & 5 reps $\times 3$ sets \\
\hline & & - Head moving while fixing eyes on complex targets (vertical/horizontal) & 5 reps $\times 3$ sets \\
\hline & & - Moving the eyes first then the head to the same direction & 5 reps $\times 3$ sets \\
\hline & 3 & Eye follow, gaze stability and eye-head coordination & \\
\hline & & Sitting & \\
\hline & & - Eyes following a target with neck in $45^{\circ}$ torsion (vertical/horizontal) & 5 reps $\times 3$ sets \\
\hline & & - Head moving while fixing eyes on a word target with complex backgrounds (vertical/horizontal) & 5 reps $\times 3$ sets \\
\hline & & - Eyes and head moving to the opposite direction (vertical/horizontal) & 5 reps $\times 3$ sets \\
\hline \multirow[t]{16}{*}{ Balance control } & 1 & Static balance & \\
\hline & & Standing & \\
\hline & & - Narrow stance (firm/soft surfaces with eyes open/closed) & $30 \mathrm{~s}$ holds $\times 10$ reps \\
\hline & & - Tandem stance (firm/soft surfaces with eyes open/closed) & 30 s holds $\times 10$ reps \\
\hline & 2 & Dynamic balance and gait & \\
\hline & & Standing & \\
\hline & & - Throwing/catching a ball while tandem stance (firm/soft surfaces) & $30 \mathrm{~s}$ holds $\times 10$ reps \\
\hline & & Walking & \\
\hline & & - Normal walking with fast speed (forward/backward, side way) & 10 reps \\
\hline & & - Tandem walking (forward/backward) & 10 reps \\
\hline & 3 & Dynamic balance and gait with head movement & \\
\hline & & Standing & \\
\hline & & - Throwing/catching a ball while single leg standing (firm/soft surfaces) & $30 \mathrm{~s}$ holds $\times 10$ reps \\
\hline & & Walking & \\
\hline & & - Normal walking (forward/backward, side way) with head movement (left/right, up/down) & 10 reps \\
\hline & & $\begin{array}{l}\text { - Tandem walking (forward/backward) } \\
\text { with head movement (left/right, up/down) }\end{array}$ & 10 reps \\
\hline
\end{tabular}

head turns from side to side. The time will be measured for the intermediate $6 \mathrm{~m}$ to exclude acceleration and deceleration [42]. Each test will be performed twice with a 60 -s rest period and the mean value used in analysis. Gait speed has been shown to be a reliable measure of functional capacity (ICC for test-retest reliability $=0.90)$ [43].

Dizziness intensity Intensity of dizziness will be measured using a VAS [22]. Participants will be asked to indicate their average dizziness intensity over the past week by marking a horizontal $100 \mathrm{~mm}$ line $(0=$ no dizziness and $100=$ worst dizziness imaginable).

Neck pain intensity Neck pain intensity will be measured using a VAS. Participant will be instructed to grade their average intensity of neck pain experienced in the past week on a $0-100 \mathrm{~mm}$ horizontal line $(0 \mathrm{~mm}=$ no pain and $100 \mathrm{~mm}$ = worst pain imaginable) [44]. The VAS has been shown to have excellent test-retest reliability $(\mathrm{ICC}=0.97)$ and high validity ( $\mathrm{r}$ with a 5-point verbal descriptive scale $=0.71-0.78)$ to evaluate pain perception $[45,46]$.
Neck disability Neck disability associated with neck pain in the past week will also be measured using the NDI-TH [47]. The NDI-TH has a total of 10 sections concerning pain and activities of daily living, with a maximum score of 50. A higher score indicates greater disability. The NDI has been shown to have high validity ( $\mathrm{r}$ with the McGill pain questionnaire $=0.69-0.70$ ) and excellent test-retest reliability $(\mathrm{ICC}=0.89)$ [48].

Pain extent and location Pain drawings will be used to assess the participants' extent and location of pain, using a digital device (iPad Air 2) and custom software [49]. Participants will be instructed to draw their pain perceived during the last week using a stylus pen on body charts with different views (frontal, dorsal, lateral right and left). They will also be asked to nominate and mark the most painful site. The type, size and colour of the pen strokes will be standardized across all participants. Custom software will be used to quantify pain extent and location. This pain drawing acquisition and analysis has been shown to be a reliable tool to evaluate the location 
Table 5 Summary of outcome measures

\begin{tabular}{ll}
\hline $\begin{array}{l}\text { Primary outcome measures } \\
\text { Postural stability }\end{array}$ & Data collection instruments \\
- Sway displacement & A swaymeter \\
- Sway area & \\
Cervical joint position error & $\begin{array}{l}\text { A laser-pointer attached to a } \\
\text { lightweight headband }\end{array}$ \\
$\begin{array}{l}\text { Secondary outcome measures } \\
\text { Gait speed }\end{array}$ & 10-m walk test \\
Dizziness intensity & VAS (0-100 mm) \\
Neck pain intensity & VAS (0-100 mm) \\
Neck disability & NDI-TH (0-100) \\
Pain extent and location & iPad and custom software \\
Cervical range of motion & A CROM instrument \\
Functional ability status & PFSF (scale range 0-10) \\
Health-related quality of life & Thai SF-36 (scale range 0-100) \\
Global perceived benefit of treatment & A seven-point ordinal Likert \\
\end{tabular}

All outcome measures will be recorded at baseline, immediately after intervention, 3, 6 and 12 months follow-ups. VAS Visual analogue scale, NDI-TH Neck disability index-Thai version, Thai SF-36 Thai version of short form 36, CROM Cervical range of motion, PFSF The patient-specific functional scale

and extent of pain in neck pain (ICC for test-retest reliability $=0.92)[49,50]$.

Cervical range of motion A cervical range of motion (CROM) goniometer (Performance Attainment Associates, USA) will be used to assess cervical range of motion in flexion, extension, left-right lateral flexion and left-right rotation. Participants will be seated upright and asked to actively move their neck in each direction three times. Any pain or dizziness provoked will be recorded on a 0-10 NRS. The CROM has been shown to have excellent testretest reliability (ICCs $=0.89-0.98)$ and high validity ( $\mathrm{r}$ with Fastrak motion analysis system $=0.93-0.98)[51]$.

Functional ability status The patient-specific functional scale (PSFS) will be used to assess participants' functional status [52]. Participants will be asked to nominate 3 to 5 activities that they are unable to do or having difficulty doing because of their neck pain. These activities will be rated on a $0-10$ scale, where 0 is unable to perform the activity and 10 is able to perform the activity at same. An average of all activities scores will be used for analysis. The PSFS has been shown to have high validity ( $\mathrm{r}$ with $\mathrm{NDI}=0.73-0.83)$ and excellent test-retest reliability $(\mathrm{ICC}=0.92)[52]$.

Health-related quality of life The Thai version of Short Form-36 will be used to assess participants' healthrelated quality of life. The instrument has been shown to have moderate to good internal consistency reliability
(Cronbach's $\alpha=0.55-0.80$ ) and good discriminant validity for use in a general population [53]. It contains 36 questions, divided into 8 dimensions of quality of life. These include physical functioning (10 items), role limitations due to physical health problems (4 items), social functioning (2 items), bodily pain ( 2 items), general mental health (5 items), vitality (4 items), role limitations due to emotional health (3 items), general health perceptions (5 items) and reported health transition ( 1 item). The scores for each question will be the weighted sum of the questions in each dimension. Scores range from 0 to 100 , with a higher score indicating better health status.

Global perceived benefit of treatment A seven-point ordinal Likert scale will be used to allow the participant to express how much they perceived a benefit from the treatment. The scale ranges from 1 (extremely dissatisfied) to 7 (extremely satisfied) [54].

\section{Randomization and allocation concealment}

All eligible participants will be randomly allocated to one of four intervention groups: i) local neck treatment, ii) local treatment plus sensorimotor control exercises, iii) local treatment plus balance exercises, or iv) local treatment plus sensorimotor control and balance exercises. Randomization will be undertaken by an independent person with no other involvement in the trial. Random sequence will be generated by a computer permuted blocks of eight, stratified by age ( $\leq$ or $>45$ years old) and dizziness (yes or no), with allocation ratio 1:1:1:1. Allocation will be concealed in sequentially numbered, sealed, opaque envelopes.

\section{Blinding}

The baseline and follow-up assessments will be performed by an independent assessor who is blinded to treatment allocation. The physiotherapists providing the intervention will not be blinded to treatment but will be blinded to outcome assessments throughout the trial.

\section{Anticipated dates of trial commencement and completion}

Recruitment and training of the physiotherapists was undertaken in May 2017 and recruitment of participants has commenced. All participants are expected to have completed the study by end 2019 .

\section{Sample size}

The sample size estimates are calculated based on the primary outcomes (postural stability and cervical JPE) from baseline to follow-ups. According to our previous data, we consider a sample size that gives $80 \%$ power with a $5 \%$ confidence level to detect a significant difference of $21.9 \mathrm{~cm}^{2}(\mathrm{SD}=12.3)$ for postural sway and $4.5^{\circ}$ 
$(\mathrm{SD}=3.2)$ for JPE. Sample size estimates were performed using both two-way ANOVA and repeated measure ANOVA (two-tailed) and the optimum number of 35 participants per group is required. To allow for $20 \%$ drop out rate, a total sample size of 168 participants (42 per group) will be recruited for this trial.

\section{Statistical analysis}

SPSS version 17.0 or higher will be used for statistical analysis. Descriptive statistics will be used to describe demographic data and baseline characteristics and follow-ups for each treatment group. Two-way mixed ANOVA will be used to determine within-subject and between subject variables. Main effects for independent variables (local treatment/sensorimotor exercise and local treatment/balance exercise) and the intervention effects of the independent variables immediately after treatment and at 3, 6 and 12 month follow-ups will be analyzed. This allows the individual effects of sensorimotor exercise and balance exercise to be examined as well as whether there will be an additive effect of applying both sensorimotor and balance exercises in a multimodal treatment. Differences in mean change (baseline minus follow-up) will be compared between groups using baseline values of the outcomes as covariates.

Effect sizes will be calculated by taking the difference in mean changes in the primary outcomes between the intervention groups and control group (local neck treatment alone). An effect size of 0.2 will be regarded as small, 0.5 as medium and 0.8 as large [55]. Main comparative analysis for primary and secondary outcomes will be performed using an intention-to-treat approach. To address missing data, multiple imputation will be performed as a sensitivity analysis. The significance level will be set at 0.05 .

\section{Discussion}

Neck pain is a common health problem and is, along with low back pain, the world's leading cause of years lived with disability [56]. To be effective, treatment must address not only the symptoms but also the impairments associated with neck pain. An effective treatment will help improve chances of a full recovery and prevent a recurrence of neck pain. This trial is the first to combine local neck treatment (manual therapy/therapeutic exercise) and specific approaches that target sensorimotor control and balance. The outcome of this trial will significantly facilitate informed decision making for the prevention and management of chronic neck pain.

This trial will investigate the effects of local neck treatment with and without tailored sensorimotor and balance exercise programs. The strengths of the study design are the pragmatic nature of treatment delivery towards clinical physiotherapy practices. Additionally, the exercise programs are individualized according to ongoing progress monitoring. It is expected that the findings of this trial will lead to improved clinical practice guidelines for persons with neck pain with impaired joint position sense and balance.

\begin{abstract}
Abbreviations
ANOVA: Analysis of variance; APmax: Maximum anterior-posterior;

BPPV: Benign paroxysmal positional vertigo; CCF: Craniocervical flexor; CONSORT: Consolidated standards of reporting trials; CROM: Cervical range of motion; ICCs: Intraclass correlation coefficients; JPE: Joint position error; JPS: Joint position sense; MLmax: Maximum medial-lateral; NDI-TH: Neck disability index-Thai version; NRS: Numerical rating scales; PFSF: Patientspecific functional scale; SD: Standard deviation; SPSS: Statistical package for the social sciences; Thai SF-36: Thai version of short form 36; USA: United States of America; VAS: Visual analogue scale
\end{abstract}

\section{Acknowledgements}

Not applicable.

\section{Funding}

This trial was granted by Faculty of Associated Medical Sciences, Chiang Mai University (AMS 2560).

\section{Availability of data and materials} Not applicable.

\section{Authors' contributions}

MS, GJ, JT, MB, DF, and SU have made contribution to the conception of the study, acquisition of data, or analysis and interpretation of data. MS, GJ, JT, and SU have involved in drafting the manuscript and revising it critically for important intellectual content. All authors have read and approved the final version of the manuscript.

\section{Ethics approval and consent to participate}

This trial was approved by the ethical review committee for research in humans, Faculty of Associated Medical Sciences, Chiang Mai University (AMSEC-60EX-018:175/2560). The trial was conducted in accordance with the Declaration of Helsinki. All participants will be provided information about the study and enrolled into the trial if they meet all eligibility criteria and voluntarily sign an informed consent statement.

Consent for publication

Not applicable.

\section{Competing interests}

The authors declare that they have no competing interests.

\section{Publisher's Note}

Springer Nature remains neutral with regard to jurisdictional claims in published maps and institutional affiliations.

\section{Author details}

${ }^{1}$ Department of Physical Therapy, Faculty of Associated Medical Sciences, Chiang Mai University, Chiang Mai, Thailand. ${ }^{2}$ Physiotherapy, School of Health and Rehabilitation Sciences, The University of Queensland, St Lucia, Brisbane, Australia. ${ }^{3}$ Rehabilitation Research Laboratory 2rLab, Department of Business Economics Health and Social Care, University of Applied Sciences and Arts of Southern Switzerland, Manno, Switzerland. ${ }^{4}$ Centre of Precision Rehabilitation for Spinal Pain (CPR Spine), School of Sport, Exercise and Rehabilitation Sciences, College of Life and Environmental Sciences, University of Birmingham, Birmingham, UK. 
Received: 15 August 2017 Accepted: 6 February 2018 Published online: 13 February 2018

\section{References}

1. Daffner SD, Hilibrand AS, Hanscom BS, Brislin BT, Vaccaro AR, Albert TJ Impact of neck and arm pain on overall health status. Spine (Phila Pa 1976). 2003:28(17):2030-5.

2. Rebbeck T, Sindhusake D, Cameron ID, Rubin G, Feyer AM, Walsh J, et al. A prospective cohort study of health outcomes following whiplash associated disorders in an Australian population. Inj Prev. 2006;12(2):93-8.

3. Cote P, Cassidy JD, Carroll LJ, Kristman V. The annual incidence and course of neck pain in the general population: a population-based cohort study. Pain. 2004;112(3):267-73.

4. Picavet HS, Schouten JS. Musculoskeletal pain in the Netherlands: prevalences, consequences and risk groups, the DMC(3)-study. Pain. 2003; 102(1-2):167-78.

5. Brandt T. Vertigo: its multisensory syndromes. 1st ed. London: SpringerVerlag; 1991.

6. Paulus I, Brumagne S. Altered interpretation of neck proprioceptive signals in persons with subclinical recurrent neck pain. J Rehabil Med. 2008;40(6):426-32.

7. Treleaven J. Sensorimotor disturbances in neck disorders affecting postural stability, head and eye movement control. Man Ther. 2008;13(1):2-11.

8. Treleaven J, Jull G, LowChoy N. The relationship of cervical joint position error to balance and eye movement disturbances in persistent whiplash Man Ther. 2006;11(2):99-106.

9. Treleaven J, Jull G, Sterling M. Dizziness and unsteadiness following whiplash injury: characteristic features and relationship with cervical joint position error. J Rehabil Med. 2003:35(1):36-43.

10. Field S, Treleaven J, Jull G. Standing balance: a comparison between idiopathic and whiplash-induced neck pain. Man Ther. 2008;13(3):183-91.

11. Jorgensen MB, Skotte JH, Holtermann A, Sjogaard G, Petersen NC, Sogaard K. Neck pain and postural balance among workers with high postural demands - a cross-sectional study. BMC Musculoskelet Disord. 2011; https://doi.org/10.1186/1471-2474-12-176.

12. Kristjansson E, Dall'Alba P, Jull G. A study of five cervicocephalic relocation tests in three different subject groups. Clin Rehabil. 2003;17(7):768-74

13. Revel $M$, Andre-Deshays $C$, Minguet $M$. Cervicocephalic kinesthetic sensibility in patients with cervical pain. Arch Phys Med Rehabil. 1991;72(5):288-91.

14. Kendall JC, Boyle E, Hartvigsen J, Hvid LG, Azari MF, Skjodt M, et al. Neck pain, concerns of falling and physical performance in community-dwelling Danish citizens over 75 years of age: a cross-sectional study. Scand J Public Health. 2016; [Epub ahead of print].

15. Poole E, Treleaven J, Jull G. The influence of neck pain on balance and gait parameters in community-dwelling elders. Man Ther. 2008;13(4):317-24.

16. Oka H, Matsudaira K, Fujii T, Okazaki H, Shinkai Y, Tsuji Y, et al. Risk factors for prolonged treatment of whiplash-associated disorders. PLoS One. 2015; https://doi.org/10.1371/journal.pone.0132191.

17. Cobo EP, Mesquida ME, Fanegas EP, Atanasio EM, Pastor MB, Pont CP, et al. What factors have influence on persistence of neck pain after a whiplash? Spine. 2010;35(9):E338-43.

18. Jull GA, Stanton WR. Predictors of responsiveness to physiotherapy management of cervicogenic headache. Cephalalgia. 2005;25(2):101-8

19. Phillips LA, Carroll LJ, Cassidy JD, Cote P. Whiplash-associated disorders: who gets depressed? Who stays depressed? Eur Spine J. 2010;19(6):945-56.

20. Miller J, Gross A, D'Sylva J, Burnie SJ, Goldsmith CH, Graham N, et al. Manual therapy and exercise for neck pain: a systematic review. Man Ther. 2010; 15(4):334-54.

21. Schroeder J, Kaplan L, Fischer DJ, Skelly AC. The outcomes of manipulation or mobilization therapy compared with physical therapy or exercise for neck pain: a systematic review. Evid based. Spine J. 2013;4(1):30-41.

22. Reid SA, Rivett DA, Katekar MG, Callister R. Comparison of mulligan sustained natural apophyseal glides and maitland mobilizations for treatment of cervicogenic dizziness: a randomized controlled trial. Phys Ther. 2014;94(4):466-76.

23. Treleaven J, Peterson G, Ludvigsson ML, Kammerlind AS, Peolsson A Balance, dizziness and proprioception in patients with chronic whiplash associated disorders complaining of dizziness: a prospective randomized study comparing three exercise programs. Man Ther. 2016;22:122-30.

24. Reid SA, Callister R, Katekar MG, Rivett DA. Effects of cervical spine manual therapy on range of motion, head repositioning, and balance in participants with cervicogenic dizziness: a randomized controlled trial. Arch Phys Med Rehabil. 2014;95(9):1603-12.

25. Uthaikhup S, Assapun J, Watcharasaksilp K, Jull G. Effectiveness of physiotherapy for seniors with recurrent headaches associated with neck pain and dysfunction: a randomized controlled trial. Spine J. 2017;17(1):46-55.

26. Jull G, Trott P, Potter H, Zito G, Niere K, Shirley D, et al. A randomized controlled trial of exercise and manipulative therapy for cervicogenic headache. Spine (Phila Pa 1976). 2002;27(17):1835-43.

27. Reid SA, Callister R, Snodgrass SJ, Katekar MG, Rivett DA. Manual therapy for cervicogenic dizziness: long-term outcomes of a randomised trial. Man Ther. 2015;20(1):148-56

28. Kristjansson E, Treleaven J. Sensorimotor function and dizziness in neck pain: implications for assessment and management. J Orthop Sports Phys Ther. 2009;39(5):364-77.

29. Beinert $K$, Taube $\mathbf{W}$. The effect of balance training on cervical sensorimotor function and neck pain. J Mot Behav. 2013;45(3):271-8.

30. Humphreys BK, Irgens $P$. The effect of a rehabilitation exercise program on head repositioning accuracy and reported levels of pain in chronic neck pain subjects. J Whiplash Relat Disord. 2002;1(1):99-112.

31. Jull G, Falla D, Treleaven J, Hodges P, Vicenzino B. Retraining cervical joint position sense: the effect of two exercise regimes. J Orthop Res. 2007;25(3):404-12.

32. Revel $M$, Minguet $M$, Gregoy $P$, Vaillant J, Manuel JL. Changes in cervicocephalic kinesthesia after a proprioceptive rehabilitation program in patients with neck pain: a randomized controlled study. Arch Phys Med Rehabil. 1994;75(8):895-9.

33. Schulz KF, Altman DG, Moher D. CONSORT group. CONSORT 2010 statement: updated guidelines for reporting parallel group randomised trials. Int J Surg. 2011;9(8):672-7.

34. Roren A, Mayoux-Benhamou MA, Fayad F, Poiraudeau S, Lantz D, Revel M. Comparison of visual and ultrasound based techniques to measure head repositioning in healthy and neck-pain subjects. Man Ther. 2009;14(3):270-7.

35. Treleaven J, Jull G, Lowchoy N. Standing balance in persistent whiplash: a comparison between subjects with and without dizziness. J Rehabil Med. 2005:37(4):224-9.

36. Treleaven J, Murison R, Jull G, LowChoy N, Brauer S. Is the method of signal analysis and test selection important for measuring standing balance in subjects with persistent whiplash? Gait Posture. 2005;21(4):395-402.

37. Jull G, Amiri M, Bullock-Saxton J, Darnell R, Lander C. Cervical musculoskeletal impairment in frequent intermittent headache. Part 1 : subjects with single headaches. Cephalalgia. 2007;27(7):793-802.

38. Sturnieks DL, Arnold R, Lord SR. Validity and reliability of the swaymeter device for measuring postural sway. BMC Geriatr. 2011; https://doi.org/10. 1186/1471-2318-11-63.

39. Shumway-Cook A, Horak FB. Assessing the influence of sensory interaction of balance. Suggestion from the field. Phys Ther. 1986;66(10):1548-50.

40. Yu $L$, Stokell R, Treleaven J. The effect of neck torsion on postural stability in subjects with persistent whiplash. Man Ther. 2011;16(4):339-43.

41. Swait $G$, Rushton $A B$, Miall RC, Newell D. Evaluation of cervical proprioceptive function: optimizing protocols and comparison between tests in normal subjects. Spine (Phila Pa 1976). 2007;32(24):E692-701.

42. Lindemann U, Najafi B, Zijlstra W, Hauer K, Muche R, Becker C, et al. Distance to achieve steady state walking speed in frail elderly persons. Gait Posture. 2008:27(1):91-6.

43. Bohannon RW. Comfortable and maximum walking speed of adults aged 20-79 years: reference values and determinants. Age Ageing. 1997;26(1):15-9.

44. Kamper SJ, Grootjans SJ, Michaleff ZA, Maher CG, McAuley JH, Sterling M. Measuring pain intensity in patients with neck pain: does it matter how you do it? Pain Pract. 2015;15(2):159-67.

45. Bijur PE, Silver W, Gallagher EJ. Reliability of the visual analog scale for measurement of acute pain. Acad Emerg Med. 2001;8(12):1153-7.

46. Hawker GA, Mian S, Kendzerska T, French M. Measures of adult pain: visual analog scale for pain (VAS pain), numeric rating scale for pain (NRS pain), McGill pain questionnaire (MPQ), short-form McGill pain questionnaire (SF$M P Q)$, chronic pain grade scale (CPGS), short form-36 bodily pain scale (SF$36 \mathrm{BPS})$, and measure of intermittent and constant osteoarthritis pain (ICOAP). Arthritis Care Res (Hoboken). 2011:63:240-52.

47. Uthaikhup S, Paungmali A, Pirunsan U. Validation of thai versions of the neck disability index and neck pain and disability scale in patients with neck pain. Spine (Phila Pa 1976). 2011;36(21):E1415-21.

48. Vernon $\mathrm{H}$, Mior S. The neck disability index: a study of reliability and validity. J Manip Physiol Ther. 1991;14(7):409-15. 
49. Barbero M, Moresi F, Leoni D, Gatti R, Egloff M, Falla D. Test-retest reliability of pain extent and pain location using a novel method for pain drawing analysis. Eur J Pain. 2015;19(8):1129-38.

50. Margolis RB, Chibnall JT, Tait RC. Test-retest reliability of the pain drawing instrument. Pain. 1988;33(1):49-51.

51. Audette I, Dumas JP, Cote JN, De Serres SJ. Validity and between-day reliability of the cervical range of motion (CROM) device. J Orthop Sports Phys Ther. 2010;40(5):318-23.

52. Westaway MD, Stratford PW, Binkley JM. The patient-specific functional scale: validation of its use in persons with neck dysfunction. J Orthop Sports Phys Ther. 1998;27(5):331-8.

53. Lim LL, Seubsman SA, Sleigh A. Thai SF-36 health survey: tests of data quality, scaling assumptions, reliability and validity in healthy men and women. Health Qual Life Outcomes 2008. doi: https://doi.org/10.1186/14777525-6-52.

54. Bombardier C. Outcome assessments in the evaluation of treatment of spinal disorders: summary and general recommendations. Spine (Phila Pa 1976). 2000;25(24):3100-3.

55. Cohen J. Statistical power analysis for the behavioural sciences. London: Academic Press; 1977

56. GBD 2015 Disease and Injury Incidence and Prevalence Collaborators. Global, regional, and national incidence, prevalence, and years lived with disability for 310 diseases and injuries, 1990-2015: a systematic analysis for the global burden of disease study 2015. Lancet. 2016;388(10053):1545-602.

57. Maitland GD, Hengeveld E, Banks K, Anglaise K. Vertebral manipulation. 7th ed. Oxford: Butterworth-Heinemann; 2005.

58. Beer A, Treleaven J, Jull G. Can a functional postural exercise improve performance in the cranio-cervical flexion test?-a preliminary study. Man Ther. 2012;17(3):219-24.

59. Jull G, Sterling M, Falla D, Treleaven J, O'Leary S. Whiplash, headache, and neck pain. Edinburgh: Churchill Livingstone; 2008.

\section{Submit your next manuscript to BioMed Central and we will help you at every step:}

- We accept pre-submission inquiries

- Our selector tool helps you to find the most relevant journal

- We provide round the clock customer support

- Convenient online submission

- Thorough peer review

- Inclusion in PubMed and all major indexing services

- Maximum visibility for your research

Submit your manuscript at www.biomedcentral.com/submit 